\title{
The Intergenerational Transmission of Divorce: A Fifteen- Country Study with the Fertility and Family Survey
}

Andreas Diekmann and Kurt Schmidheiny

March 2008 (first version: 2004)

ETH Zurich, Chair of Sociology

SEW E 21, Scheuchzerstrasse 70

8092 Zurich, Switzerland

Tel. +41446325556

Fax +41446321054

info@soz.gess.ethz.ch

www.socio.ethz.ch 


\title{
The Intergenerational Transmission of Divorce: \\ A Fifteen-Country Study with the Fertility and Family Survey*
}

\author{
Andreas Diekmann \\ Sociology, Swiss Federal Institute of Technology (ETH) \\ andreas.diekmann@soz.gess.ethz.ch
}

Kurt Schmidheiny

Universitat Pompeu Fabra

kurt.schmidheiny@upf.edu

March 31, 2008

(a first draft of this paper was presented at the congress of the Population Association of America 2004, revised 2006)

\begin{abstract}
Studies mainly from the United States provide evidence that children of divorced parents face a higher risk of divorce in their own marriages. We estimate and analyze the effects of divorce transmission using comparative individual data from the United Nations for 13 eastern and western European countries as well as for Canada and the United States. We find substantial and highly statistically significant transmission effects in all samples. This shows that the intergenerational transmission of divorce is a widespread phenomenon observed without a single exception in our data covering a large number of countries with differing historical, institutional, and cultural contexts.
\end{abstract}

Keywords: Divorce, Divorce Risk, Intergenerational Transmission, Consequences of Divorce, Child Well-being.

\footnotetext{
* The authors wish to thank the Advisory Group of the FFS program for its permission, granted under identification number 81 , to use the FFS data on which this study is based. We are also very much indebted to Elisabeth Coutts and Hartmut Esser for valuable comments.
} 


\section{Introduction}

Studies from the United States provide evidence that children of divorced parents face a higher risk of divorce in their own marriages, although there is controversy about the reasons for this effect (Amato 1996; Bumpass and Sweet 1972; Glenn and Kramer 1987; Greenberg and Nay 1982; Keith and Finlay 1988; Mc Lanahan and Bumpass 1988; Mott and Moore 1979; Mueller and Pope 1977; Pope and Mueller 1976; Teachman 1982; Wolfinger 1999). The effect has also been found in the Netherlands (Traag, Dronkers and Vallet 2000), West Gemany (Diekmann and Engelhardt 1999), Great Britain (Kiernan and Cherlin 1999) and France (Traag, Dronkers and Vallet 2000), although no effect was found in East Germany (Diefenbach 1997). The intergenerational transmission of divorce has contributed to the upward trend in divorce rates, and a better understanding of its effect is crucial not only to the analysis and prediction of divorce trends but also to insight into the development of children after their parents' divorce. Up to now it has not been established whether the transmission effect and its proposed explanations are generalizable to other Western countries and beyond. In this study, we estimate and analyze the effects of divorce transmission for 13 eastern and western European countries as well as for Canada and the United States. Our study is the first to conduct a systematic investigation covering a large number of countries with differing historical, institutional, and cultural contexts, thus allowing us to answer the question of whether divorce transmission is a stable and robust phenomenon observable across different cultures. Also, the analysis of patterns in divorce-related characteristics among children from divorced families sheds light on the explanation of the transmission effect.

It is by no means natural to assume that transmission effects are a universal phe- 
nomenon. One can hypothesize that these effects depend on many factors, some of them related to institutional setting (Amato and Keith 1991a,b). Custody regulations, financial support by the non-resident parent, and other aspects of divorce laws may have an impact on how well children are able to cope with their parents' divorce. Of course, these regulations vary over time and across countries. The nations in our sample also differ in terms of cultural patterns, religious beliefs and the degree to which a divorce is considered a "normal" event in the life course.

In the current study, we therefore examine the divorce transmission effect in countries that vary in terms of the above factors. We use the retrospective data on family histories from the Fertility and Family Survey to estimate transmission effects for fifteen countries, including various Western and Eastern European countries, Canada, and the United States. We also control for additional independent variables that may well affect the survey's respondent's risk of divorce. The set of control variables includes wellknown divorce risk factors such as age at the start of a union that led to marriage, birth of a child, the wife's educational level premarital cohabitation and membership in certain marriage cohorts (e.g. White 1990). Previous studies have shown that divorce risks decrease with the age at which the union that leads to marriage is commenced, while childless couples and spouses who lived together before marriage exhibit higher divorce risks than couples who have children and who did not share a household before marriage. This set of control variables may also mediate the transmission effect. Empirical studies show that if parents divorce, their offspring complete less education, marry earlier, have a greater tendency to cohabit before marriage and may invest less in a partnership than children from non-divorced families (e.g. Keith and Finlay 1988, Amato 1996, Diekmann and Engelhardt 1999). A further strength of the present study is that our data 
allow us to investigate whether the means of possible mediating variables differ systematically across countries. Finally, we have also accounted for marriage cohort membership because divorce risk in general has increased in Western countries in recent decades.

Our estimation employs the technique of event-history analysis. First, we investigate the presence or absence of transmission effects in the countries included in our study. Second, we examine whether the findings are explainable by the other divorcerelated covariates mentioned above. Finally, we explore whether there are systematic differences in the means of divorce risk factors for respondents with divorced and nondivorced parents, differences which could explain at least part of the social inheritance of divorce.

\section{Data}

The study is based on data from the Fertility and Family Survey. The FFS comprises surveys in 21 countries, but the necessary information on either the duration of the respondent's marriage or whether the respondent's parents divorced is lacking for five of those countries. Thus, with West and East Germany analyzed separately, our estimates are based on 16 data sets collected in the early 1990s in 13 European countries, Canada, and the United States. ${ }^{1}$ We confine our analysis to female respondents who were married or have previously married. With these restrictions, net sample sizes vary from 1,279 (Czech Republic) to 6,844 (U.S.).

Table A.1 in the Appendix displays the variables used and their means. Tables A.2

\footnotetext{
${ }^{1}$ Samples were drawn from the population within certain age limits. The Belgian sample covers only Flanders and the region of Brussels. For more information on the FFS and its use in comparative research, see Festy and Prioux (2002).
} 
and A.3 show the means of the variables separately for respondents whose parents did not divorce and those whose parents divorced. The variable of main interest is duration of first marriage in months. We consider a marriage terminated when it ends in divorce or permanent separation. ${ }^{2}$ For these purposes, we consider the termination date to be the date of dissolution of a common household. ${ }^{3}$

The main explanatory variable is the parents' relationship during the respondent's childhood. The dummy variable parents' divorce is set to 1 if the respondent's (natural or adoptive) parents divorced or separated after her birth. In addition to the divorce/separation of the respondent's parents, the analysis includes the family structure of the home of origin, specifically information on whether the respondent grew up with both parents, one parent or without either parent. ${ }^{4}$

Further independent variables include the respondent's marriage cohort, age at start of the union that led to her first marriage, birth of a child, her educational level and her cohabitation history. We use five-year marriage cohorts from 1970 to 1990 . The age at start of union is the age of the respondent at the time she began living with her first marriage partner. The birth of the respondent's first child is included as a time-dependent covariate. The respondent's educational level is the one attained by the date of the interview, and is measured in accordance with the international standard classification of education (ISCED). ${ }^{5}$ This scale covers seven educational levels from pre-primary (0) to

\footnotetext{
${ }^{2}$ The FFS Standard Recode File does not distinguish between legal divorce and separation.

${ }^{3}$ This definition seems reasonable as the time between the end of co-residence and the date of the legal divorce varies substantially across the different jurisdictions. Furthermore, the date of legal divorce is not reported in most FFS data sets. See Festy and Prioux (2002, p. 32) for a discussion of the comparability of FFS partnership data across countries.

${ }^{4}$ The information on composition of the home of origin varies across countries.

${ }^{5}$ Unfortunately, educational attainment at marriage is either not reported or very poorly reported for most
} 


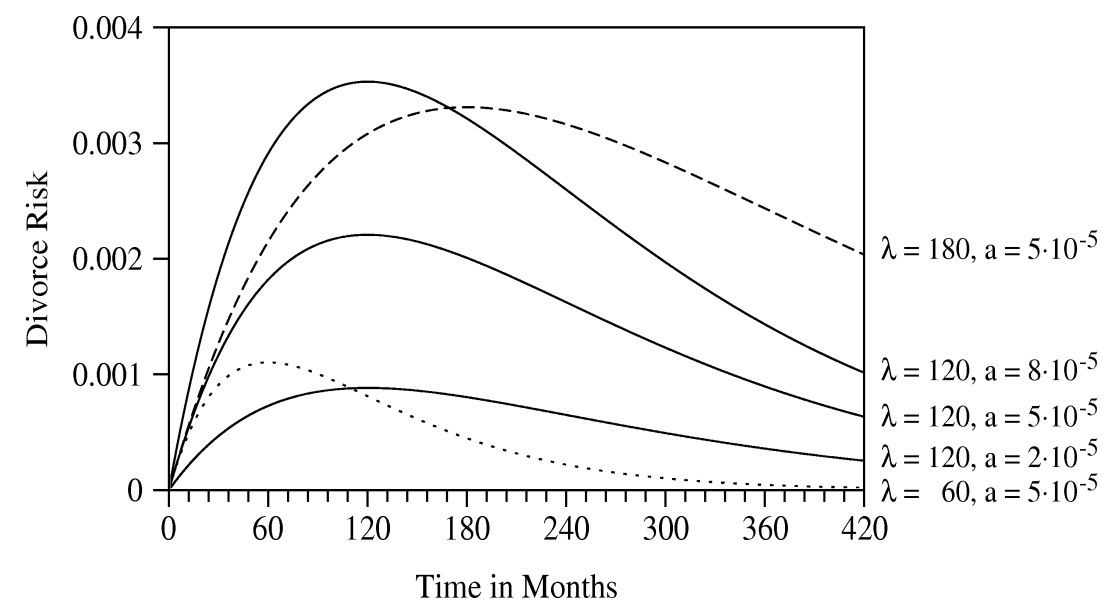

Figure 1: The sickle model of the divorce risk function. Hazard rate curves for different values of the parameterands $\lambda$ and $a$.

the second stage of tertiary (6). ${ }^{6}$ We distinguished among three levels: 'lower' (values 0 , 1 or 2 of the ISCED classification), 'medium' (ISCED 3 or 4), and 'higher' (ISCED 5 or 6). Cohabitation denotes whether the respondent had already shared a household with her first spouse before they married (see Appendix A1 for the means of the covariates).

\section{Methods}

We employ the techniques of event history analysis to estimate the effects of a respondent's parents' divorce and sociodemographic covariates on the respondent's own divorce risk.

It is well known that divorce risk increases during the initial years of marriage and decreases thereafter (see Figure 1). Because of this non-monotonic duration dependence, we model the hazard rate of divorce risk as

countries. See Festy and Prioux (2002, pp. 32) for a discussion of the limited comparability of education variables across countries in the FFS.

${ }^{6}$ The other levels of the ISCED scale are: (1) primary education or first stage of basic education, (2) lower secondary or second stage of basic education, (3) (upper) secondary education, (4) post-secondary 


$$
r(t)=a t e^{-t / \lambda}
$$

with marriage duration $t$, parameter $\lambda$ measuring time in months elapsed until maximal risk and $a=\exp \left(\beta_{0}+x_{1} \beta_{1}+\ldots+x_{k} \beta_{k}+\ldots+x_{K} \beta_{k}\right) ; x_{1}$ is a dichotomous variable indicating whether parents remained married $\left(x_{1}=0\right)$ or were divorced $\left(x_{1}=1\right), x_{2}, \ldots, x_{\mathrm{m}}$ are further covariates, and $\beta_{1}, \beta_{2}, \ldots, \beta_{m}$ are empirically estimated parameters. $\beta_{k} \cdot 100 \%$ is approximately and $\left[\exp \left(\beta_{k}\right)-1\right] \cdot 100 \%$ is exactly equal to the percentage change in the respondent's divorce risk $r(t)$ when the covariate $x_{k}$ increases by one unit. We use the maximum likelihood method to estimate the $\beta$ parameters of covariate effects and the parameter $\lambda$. Apart from the birth of the first child, all independent variables are treated as time constant. We estimate the parameters of the time-dependent covariate in the likelihood function using the method of episode splitting (Blossfeld and Rohwer 1995). ${ }^{7}$

The complete length of the episode can be observed only in marriages that ended in divorce before the interview took place. Marriages still in effect at the time of the interview or those ended by the death of a spouse are treated as censored data. Both the complete episodes and the censored ones were used to estimate the $\beta$ and $\lambda$-parameters. In the presence of censored data, the maximum likelihood method provides consistent and asymptotically normally distributed estimates of the parameters.

non-tertiary education, and (5) first stage of tertiary education. See UNESCO (1997) for more details.

${ }^{7}$ Roughly speaking, 'episode splitting' is a method for decomposing an episode like marriage duration into subintervals. Covariates remain constant within subintervals, and the likelihood function can therefore be rewritten as a product of the subinterval-specific likelihoods. For technical details see, for example, Blossfeld and Rohwer (1995). 


\section{Results}

We estimate three different models. The estimated transmission effects from those three models are summarized in Table 1 and the respective percentage effects visualized in Figure 2. Model 1 controls only for marriage cohorts, Model 2 controls for these cohorts and home of origin, and Model 3 includes the additional covariates of date of the first child's birth, cohabitation, age at start of union, and educational level (see Figure 2 and Table 1, for more detailed information see Tables A.4 to A.6 in the Appendix).

Our first finding is the universal existence of the transmission effect. Model 1 in Figure 2 shows the percentage transmission effect, i.e. $\exp (\beta 1)-1$, for children from divorced families versus respondents from non-divorced families for all samples. The effects range from $50 \%$ for Hungary and Latvia to $220 \%$ for Italy with an average effect of $103 \%$. This means that children whose parents divorced face - on average - a $103 \%$ higher risk of getting divorced than children whose parents did not divorce. The effects for all 16 data sets are substantially larger than 0 and highly significant (Spain at $\mathrm{p}<$ 0.05 , Slovenia at $p<0.01$; all other countries at $p<0.001)$. In contrast to a previous analysis (Diefenbach 1997), we also find a highly significant transmission effect for East Germany. Our analysis clearly shows that the intergenerational transmission of divorce is a widespread phenomenon observed without a single exception in formerly communist Eastern Europe, Southern (Catholic) Europe, Western Europe and North America.

Children of divorced parents usually grow up with one parent only. In the next step we therefore disentangle the effect of the parent's divorce from that of the parental home. Model 2 controls for whether the person grew up with one parent only. The two effects can be separately identified as some children lose a parent for reasons other than 


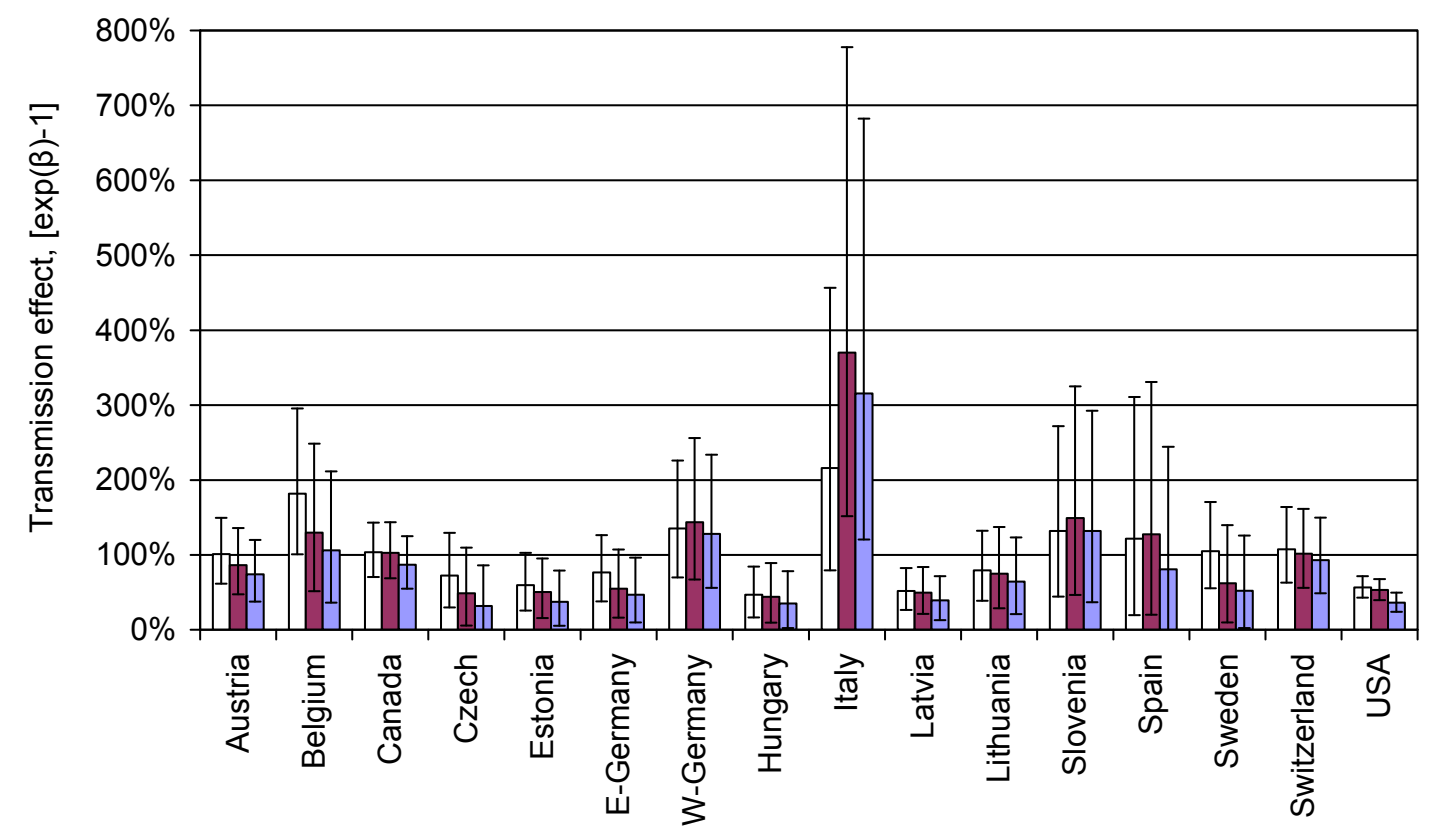

$\square$ Model 1: controlled for cohorts

$\square$ Model 2: additionally controlled for parental home

$\square$ Model 3: additionally controlled for education, age at start of union, cohabitation, children

Figure 2: The intergenerational transmission effect of divorce. Summary of estimates of $\beta_{1}$ from country specific maximum likelihood estimations of hazard rate models with different sets of control variables. Plotted is the percent effect $\exp \left(\beta_{1}\right)-1$. Reading the transmission effect (e.g., Austria): the percent effect of $101 \%$ means that children whose parents divorced have a $101 \%$ higher risk of divorce than children whose parents did not divorce. 95\% confidence interval based on (non-linear) transformation of confidence bounds of the estimated $\beta_{1}$. Full estimation results are provided in Tables A.4 to A.6 in the Appendix.

divorce. Our results show that the transmission effect is only moderately changed in all countries but Italy, where it is substantially increased. The transmission effect remains highly significant in all countries.

In model 3 we include educational level, age at start of union, cohabitation and the birth of children as additional control variables. Transmission effects are again only moder few of the respondents' parents were divorced), and remain significant at $\mathrm{p}<$ 0.05 in all countries but Spain $(\mathrm{p}<0.1)$ and the Czech Republic. This reduction is a result of controlling for cohabitation and age at start of the union, since in all countries the children of divorce cohabit more and begin unions earlier. 


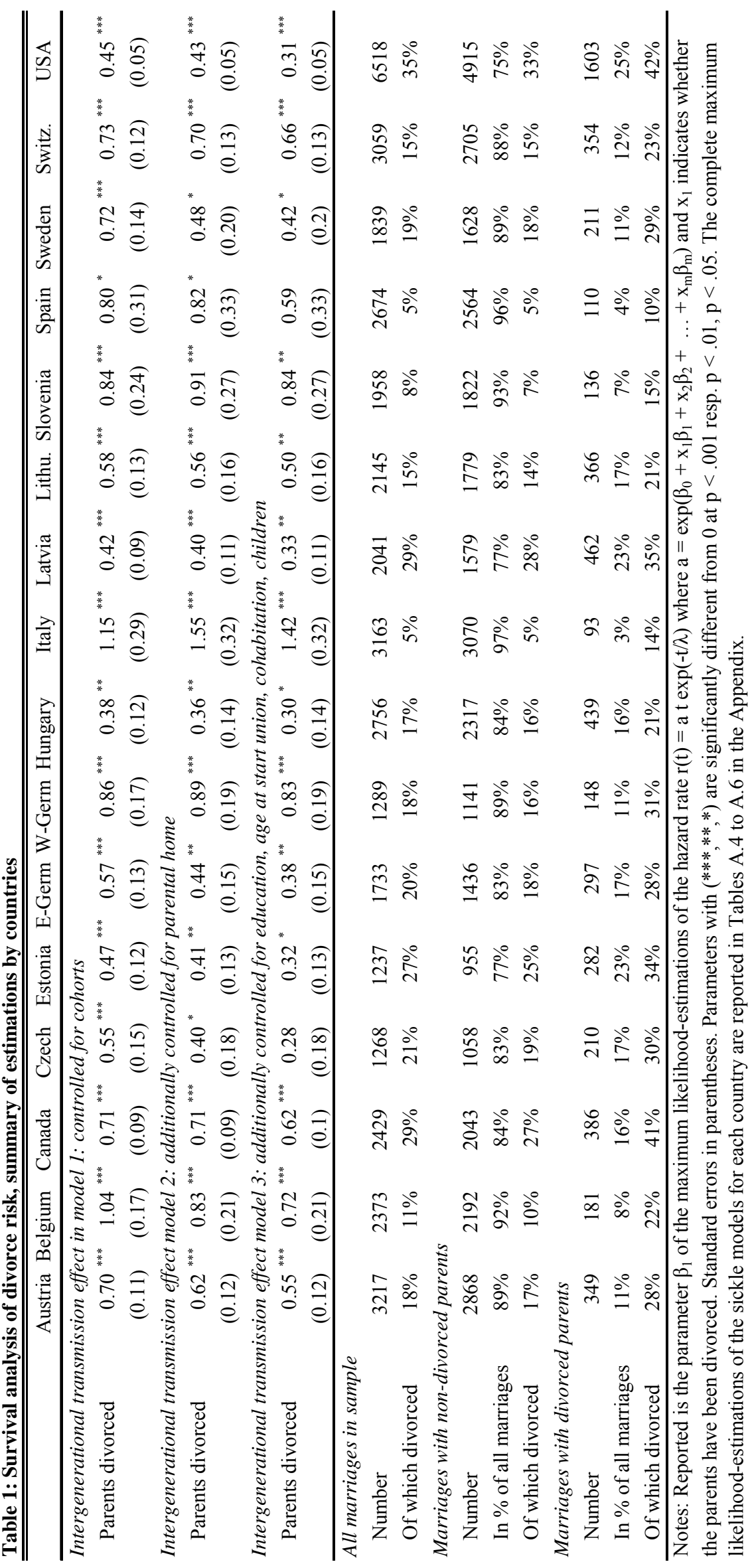


ately reduced compared to the unconditional effects in model 1, except in Italy (where

The pattern of union formation and cohabitation sheds light on the explanation of the transmission effect. In all countries but one, the estimated coefficient indicates a higher risk of divorce for couples that lived together before marriage (see Table A.6). In addition, the well-known negative effect on divorce of age at union formation shows up in all countries. At the same time, the children of divorce cohabit more frequently than respondents from non-divorced families and enter into unions at younger age in all countries (compare Tables A.2 and A.3). Although cohabitation does likely not exert a positive causal effect on divorce, the covariate is correlated with the divorce risk. Previous studies have shown that spouses living together before marriage form a selective group that is more divorce-prone than those entering into traditional marriages (Brüderl and Kalter 2001). For older marriage cohorts in particular, cohabitation signals that spouses are less committed to marriage than spouses who did not live together before marriage. The observed patterns fit well with the "low-commitment hypothesis" (Amato and DeBoer 2001, Wolfinger 2005). Accordingly, one causal pathway is that children of divorce develop more sceptical attitudes toward a long-lasting partnership, therefore choose less binding commitments when starting a union, and are ultimately more likely to divorce.

The systematic effect of parental divorce on the pattern of educational attainment is also noteworthy. In all countries except one, the children of divorced parents participate in advanced education (ISCED 5 or 6 ) to a lesser extent than respondents with nondivorced parents. Yet, as far as possible effects of this disparity on marriage stability are concerned, education is not consistently related to the respondent's divorce risk and is therefore not a mediator variable in explaining part of the transmission effect in almost 
all the countries studied. Women's education has multiple consequences on such divorce-related risk factors as labour-force participation, personal income, household income and cultural preferences. Some of these factors increase divorce risks while others may have a positive impact on marital stability. Thus, it is no surprise that we do not find a robust effect for a woman's education on marital stability for all the national data sets. Previous studies have also not reported consistent findings on the effect of a woman's level of education on her divorce risk (Dourleijn and Liefbroer 2002).

\section{Explaining cross-country variation of transmission effects}

Our estimations show substantial variation in the magnitude of the divorce transmission effect ranging from 0.38 in Hungary to 1.34 in Italy. Can these differences across counties be explained by historical, institutional and cultural differences?

We did not find any systematic pattern that related the magnitude of the transmission effect to, for example, catholic religion, former communist countries, etc. However, there is one striking relationship (see Figure 3): the transmission effect is highly negatively correlated with the divorce rates of the parent population (slope $=-3.46$, $t$ value $=4.38, \mathrm{R}^{2}=0.58$ ). This result is especially important as it seems to confirm the hypothesis that the detrimental effects of divorce on children are stronger in societies where divorce is rare and thus more likely stigmatised.

While highly appealing, we believe that this finding is an artefact for two reasons. First, the negative correlation between transmission effect and parental divorce rates found across countries is not found within countries over time: while divorce rates increased in all countries, the transmission effect decreased in only half of the countries 


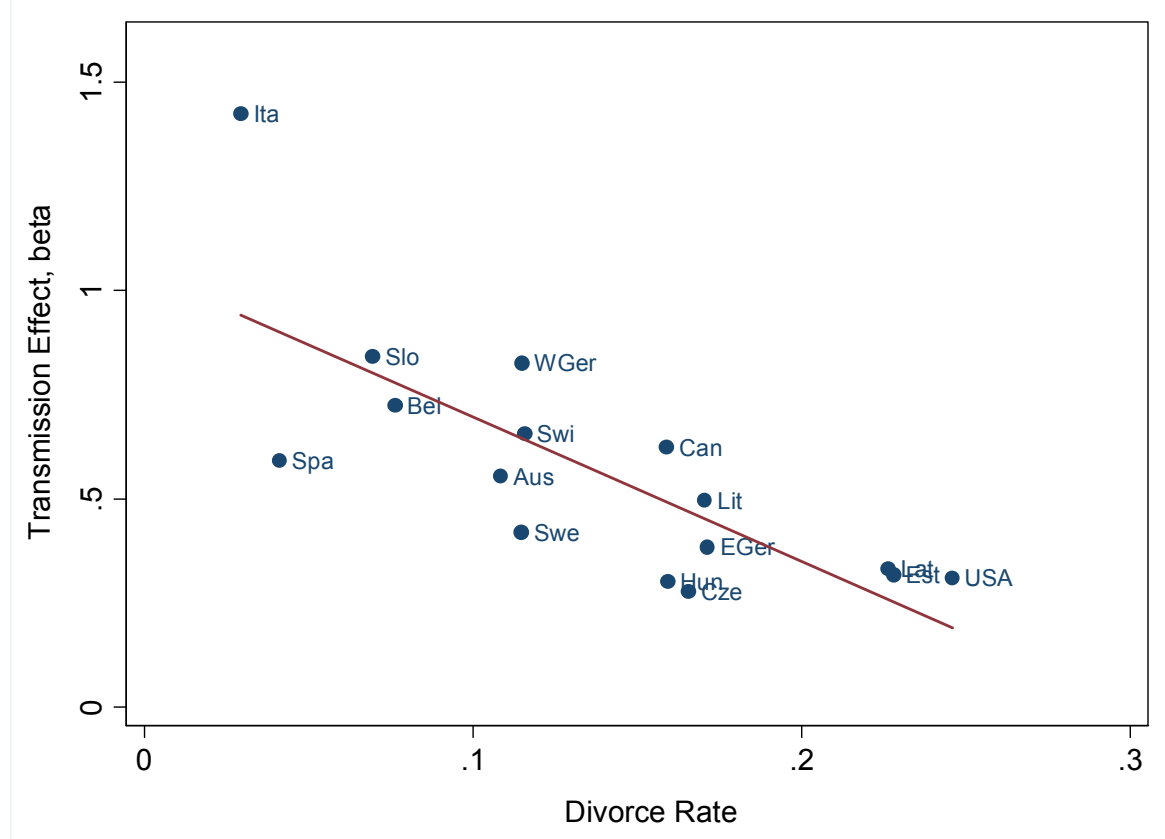

Figure 3. Intergenerational divorce transmission and divorce rates by country.

and increased in the others. ${ }^{8}$ Our scepticism is in line with Li and $\mathrm{Wu}$ (2004) who show that Wolfinger's (1999) finding of a decrease in the U.S. divorce transmission effect was flawed. Second, the negative correlation between transmission effect and parental divorce rates found for the relative increase in divorce risk is not found for the absolute increase in divorce risk: while the relative effects differ by a factor of almost 3 across countries, the absolute effects are of similar magnitude. ${ }^{9}$ Relative increases are the result of dividing absolute effects by the baseline divorce risk. The significant negative relationship between the relative transmission effect and parental divorce rates can simply be explained by the self-evident positive relationship of the left-hand side numerator (the divorce rate of the observed generation) with the explanatory variable (the divorce rate of the parents' generation).

\footnotetext{
${ }^{8}$ Detailed estimation results are available from the authors on request.

${ }^{9}$ Detailed estimation results are available from the authors on request.
} 


\section{Conclusions}

This study investigates the intergenerational transmission of divorce in 13 European countries, the United States and Canada. We analyze the cross-national data from female respondents in the Fertility and Family Survey, applying techniques of event history analysis. We find substantial and highly statistically significant transmission effects in all samples. This shows that the intergenerational transmission of divorce is a widespread phenomenon observed without a single exception in our data covering a large number of countries with differing historical, institutional, and cultural contexts.

Our study also demonstrates the presence of systematic patterns in the consequences of divorce on children's marital behaviour. Women whose parents had divorced were, in all countries, also more likely to cohabit with the men they eventually married than women who grew up with both of their parents. This finding is in keeping with previous studies, which have also noted greater rates of cohabitation among respondents with divorced parents (e.g. Amato 1996, Diekmann and Engelhardt 1999, Kiernan and Cherlin 1999). Our study adds to this finding by showing that the increased tendency to cohabit is a rather universal phenomenon, one observed - at least for female children in all the countries we studied. This result fits with Amato and DeBoer's (2001) suggestion that the children of divorce have less favourable attitudes toward marriage and therefore choose less binding commitments when starting a union. 


\section{References}

Amato, Paul R. (1996). Explaining the Intergenerational Transmission of Divorce. Journal of Marriage and the Family 58: 628 -640.

Amato, Paul R. and Danelle DeBoer (2001). The Transmission of Marital Instability Across Generations: Relationship Skills or Commitment to Marriage? Journal of Marriage and the Family 63: 1038-1051.

Amato, P. and B. Keith (1991a). Parental Divorce and the Well-Being of Children: A Meta-Analysis. Psychological Bulletin 110: 26-46.

Amato, P. and B. Keith (1991b). Parental Divorce and Adult Well-Being: A MetaAnalysis. Journal of Marriage and the Family 53/1: 43-58.

Blossfeld, Hans-Peter and Goetz Rohwer (1995). Techniques of Event History Modeling. Hillsdale, NY: Erlbaum.

Brüderl, Josef and Kalter, Frank (2001). The Dissolution of Marriages. The Role of Information and Marital-Specific Capital. Journal of Mathematical Sociology 25: 403-421.

Bumpass, Larry L. and James A. Sweet (1972). Differentials in Marital Instability. American Sociological Review 37: 754-766.

Diekmann, Andreas and Peter Mitter (1984). A Comparison of the 'Sickle Function' with Alternative Stochastic Models of Divorce Rates. In Andreas Diekmann and Peter Mitter, eds. Stochastic Models of Social Processes. Orlando, Fl.: Academic Press.

Diekmann, Andreas and Henriette Engelhardt (1999). The Social Inheritance of Divorce: Effect of Parent's Family Type in Postwar Germany. American Sociological Review 64: 783-793.

Dourleijn, Edith and Aart C. Liefbroer (2002), Unmarried Cohabitation and Union Stability. Testing the Role of Diffusion Using Data from 16 European Countries. Paper presented at the conference on "Divorce in a Cross-National Perspective. A European Research Network", Florence, November 2002.

Festy, Patrick and France Prioux (2002). An Evaluation of the Fertility and Family Surveys Project in the Countries of the UNECE Region. New York and Geneva: United Nations Economic Commission for Europe.

Glenn, Norval D. and Kathryn B. Kramer (1987). The Marriages and Divorces of the Children of Divorce. Journal of Marriage and the Family 49: 811-825.

Greenberg, Ellen F. and W. Robert Nay (1982). The Intergenerational Transmissionof Marital Instability Reconsidered. Journal of Marriage and the Family 44: 335-347.

Keith, Verna M. and Barbara Finlay (1988). The Impact of Parental Divorce on Children's Educational Attainment, Marital Timing, and Likelihood of Divorce. Journal of Marriage and the Family 50: 797-809. 
Kiernan, Kathleen E. and Andrew J. Cherlin (1999). Parental Divorce and Partnership Dissolution in Adulthood: Evidence from a British Cohort Study. Population Studies 53: 39-48.

Li, Lui-Chung Allen and Lawrence L. Wu (2004), No Trend in the Intergenerational Transmission of Divorce. Department of Sociology, New York University. Mimeo.

McLanahan, Sara and Larry Bumpass (1988). Intergenerational Consequences of Family Disruption. American Journal of Sociology 94: 130-152

Mott, Frank L. and Sylvia F. Moore (1979). The Causes of Marital Disruption among Young American Women: An Tnterdisciplinary Perspective. Journal of Marriage and the Family 41: 355-365.

Mueller, Charles W. and Hallowell Pope (1977). Marital Instability: A Study of its Transmission between Generations. Journal of Marriage and the Family 39: 83-92.

Pope, Hallowell and Charles W. Mueller (1976). The Intergenerational Transmission of Marital Instability: Comparisons by Race and Sex. Journal of Social Issues 35: 112-125.

Teachman, Jay D. (1982). Methodological Issues in the Analysis of Family Formation and Dissolution. Journal of Marriage and the Family 44: 1037-1053.

White, Lynn K. (1990). Determinants of Divorce: A Review of Research in the Eighties. Journal of Marriage and the Family 52: 904-912.

Wolfinger, Nicholas H. (1995). Trends in the Intergenerational Transmission of Divorce. Demography 36: 415-20.

Schoenmaeckers, Ronald, and Edith Lodewijcky (1999). Changes in Demographic Behaviour in Europe: Some Results from FFS-Country Reports and Suggestions for further Research. European Journal of Population 15: 207-240.

Traag, Tanja, Jaap Dronkers and Louis-André Vallet (2000). The intergenerational transmission of divorce risks in France. ASSR working paper 68, presented to the Research Committee 28 - Social Stratification of the International Sociological Association in Libourne, France May 11-14, 2000.

UNESCO (1997). ISCED. International Standard Classification of Educatio. UNESCO Institute for Statistics.

Wolfinger, Nicholas (1999). Trends in the Intergenerational Transmission of Divorce. Demography 36: 415-420. 


\section{Appendix: Estimation Results}

Table A.1: Samples and descriptive statistics

Table A.2: Descriptive statistics when Parents are not divorced

Table A.3: Descriptive statistics when Parents are divorced

Table A.4: Transmission effect of divorce, controlled for cohorts (Model 1)

Table A.5: Transmission effect of divorce, additionally controlled for parental home (Model 2)

Table A.6: Transmission effect of divorce, additionally controlled for education, age at start union, cohabitation, children (Model 3) 


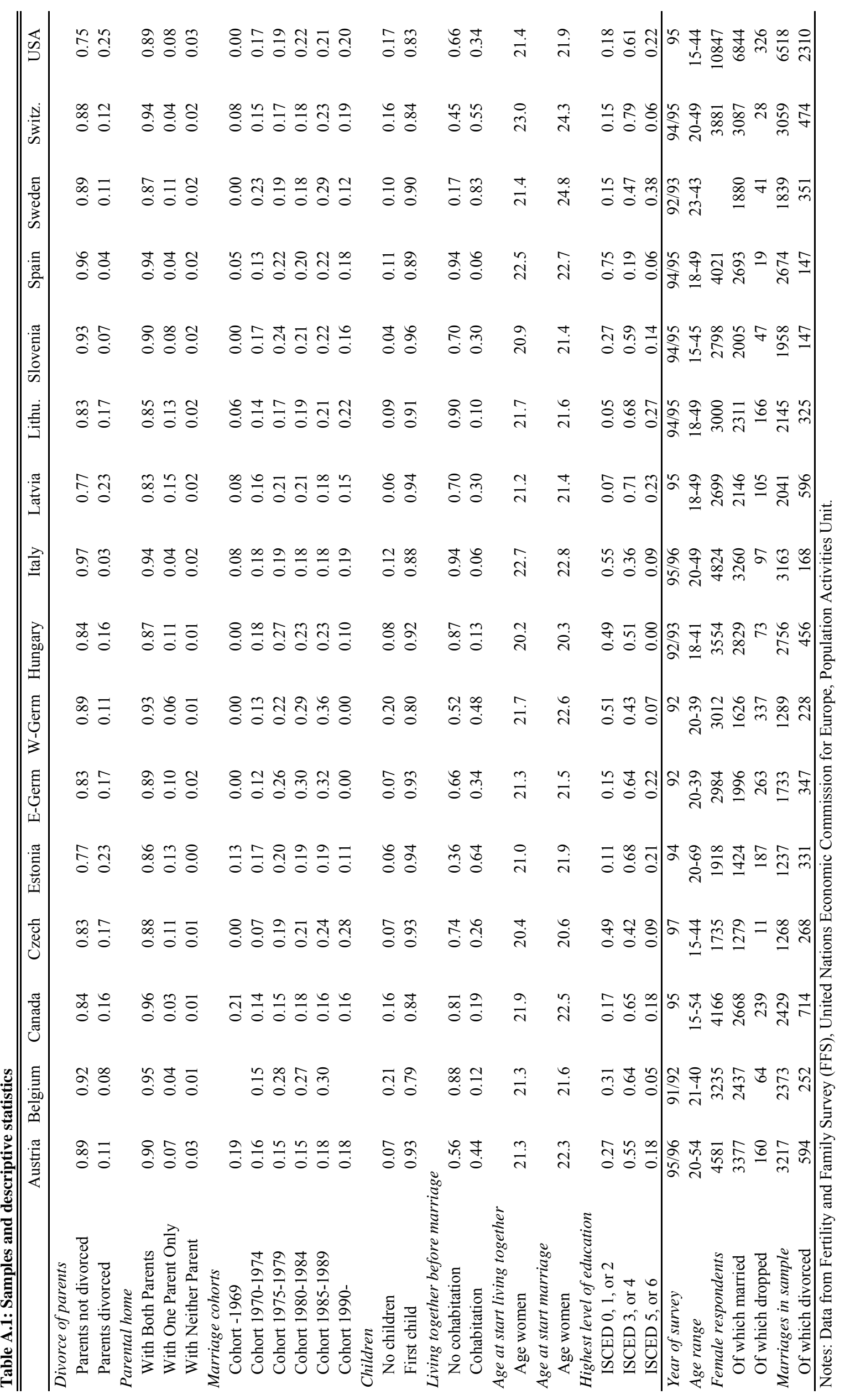




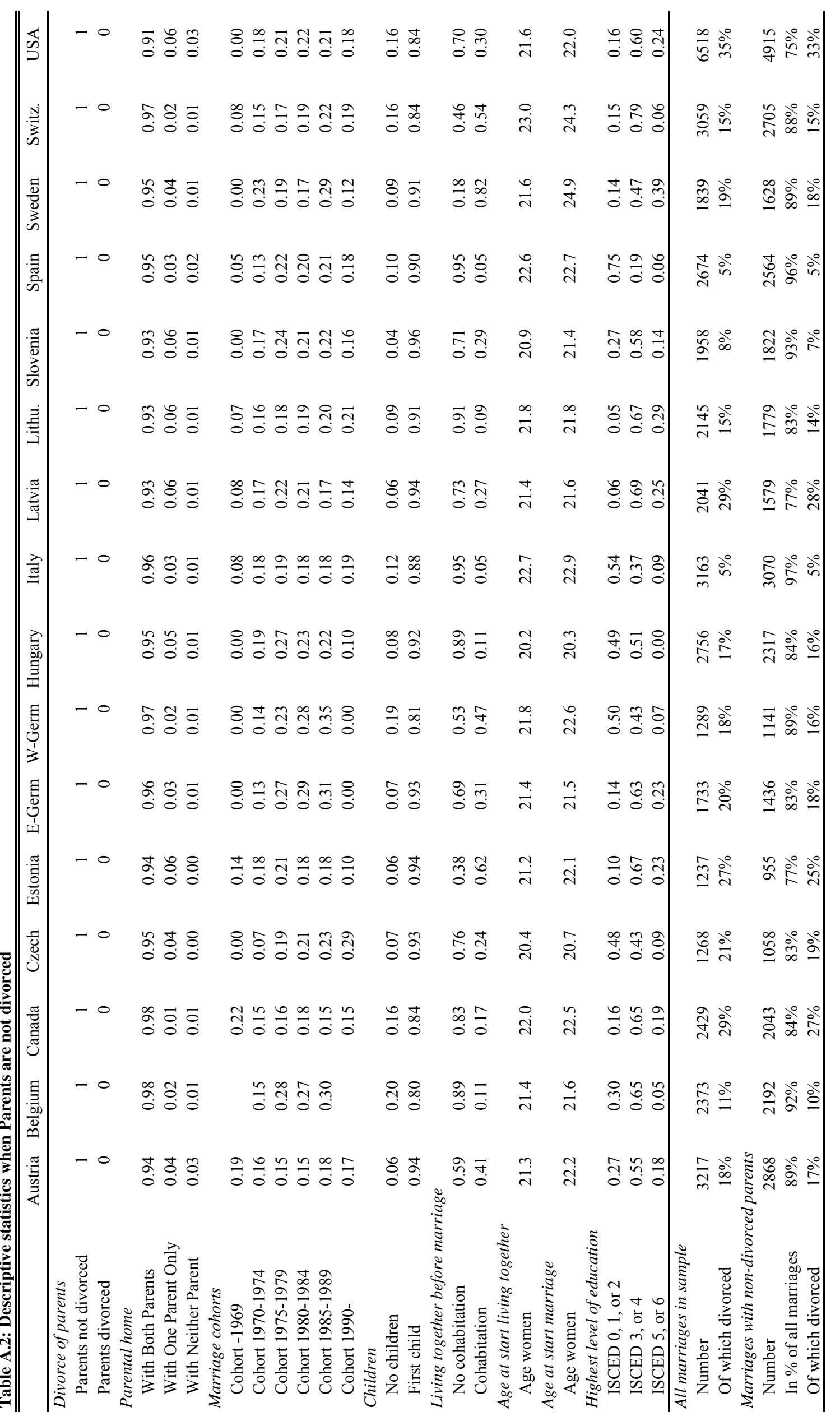




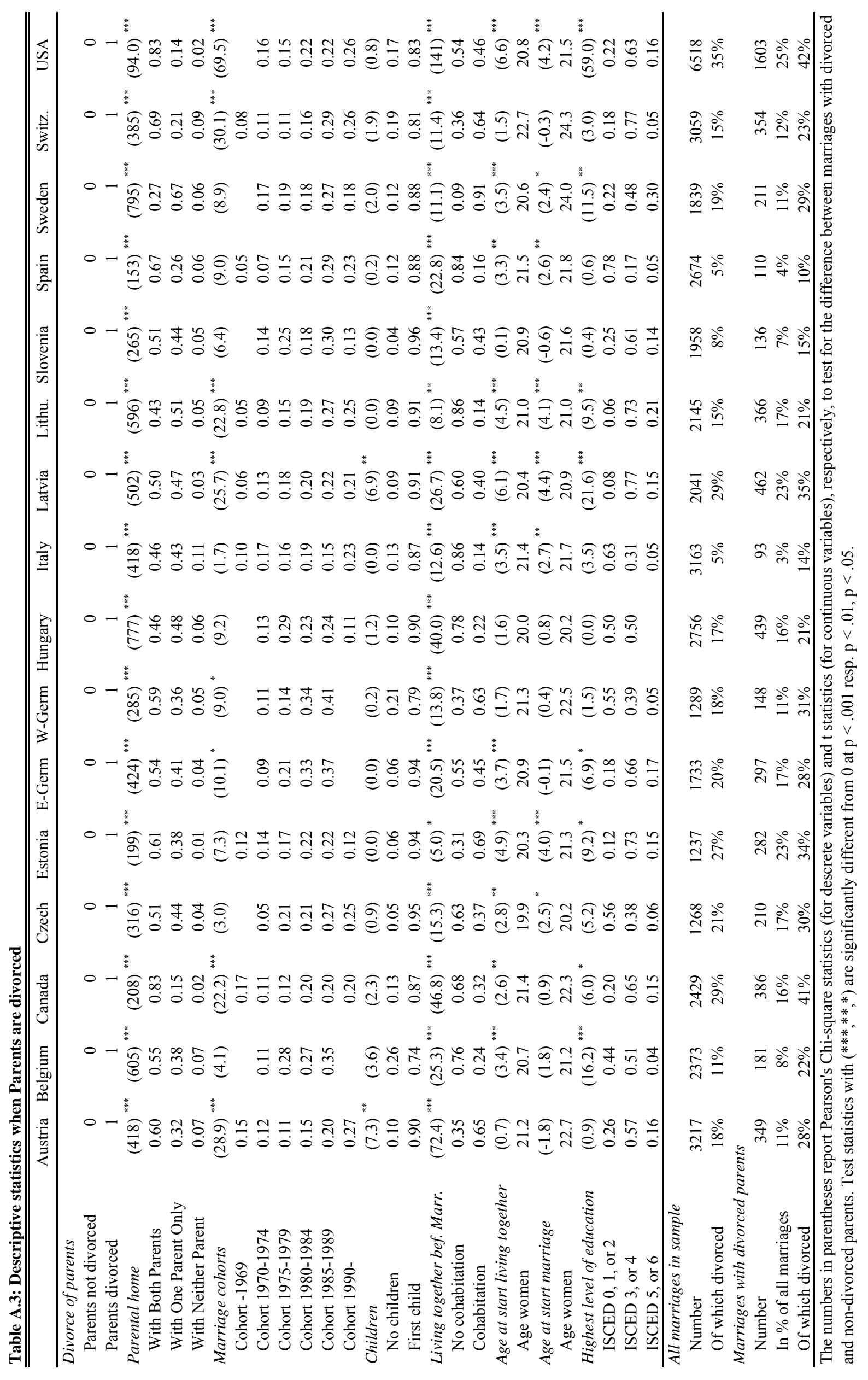




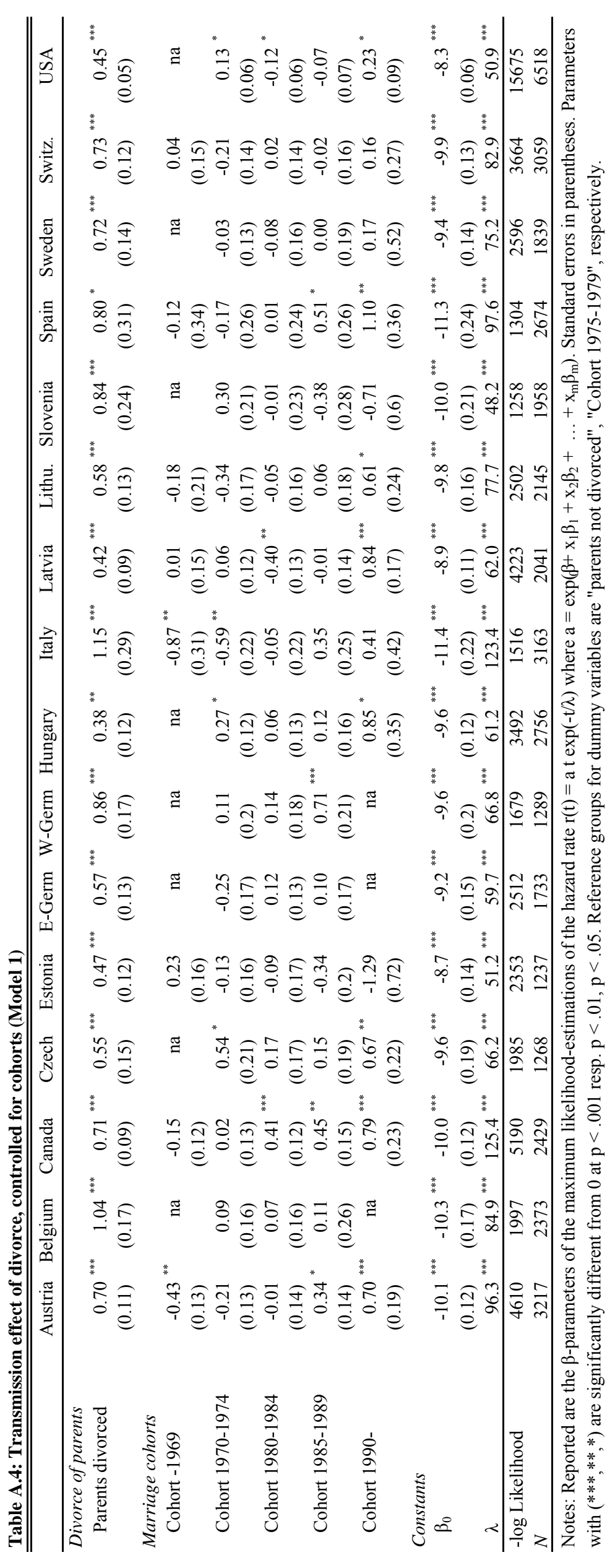




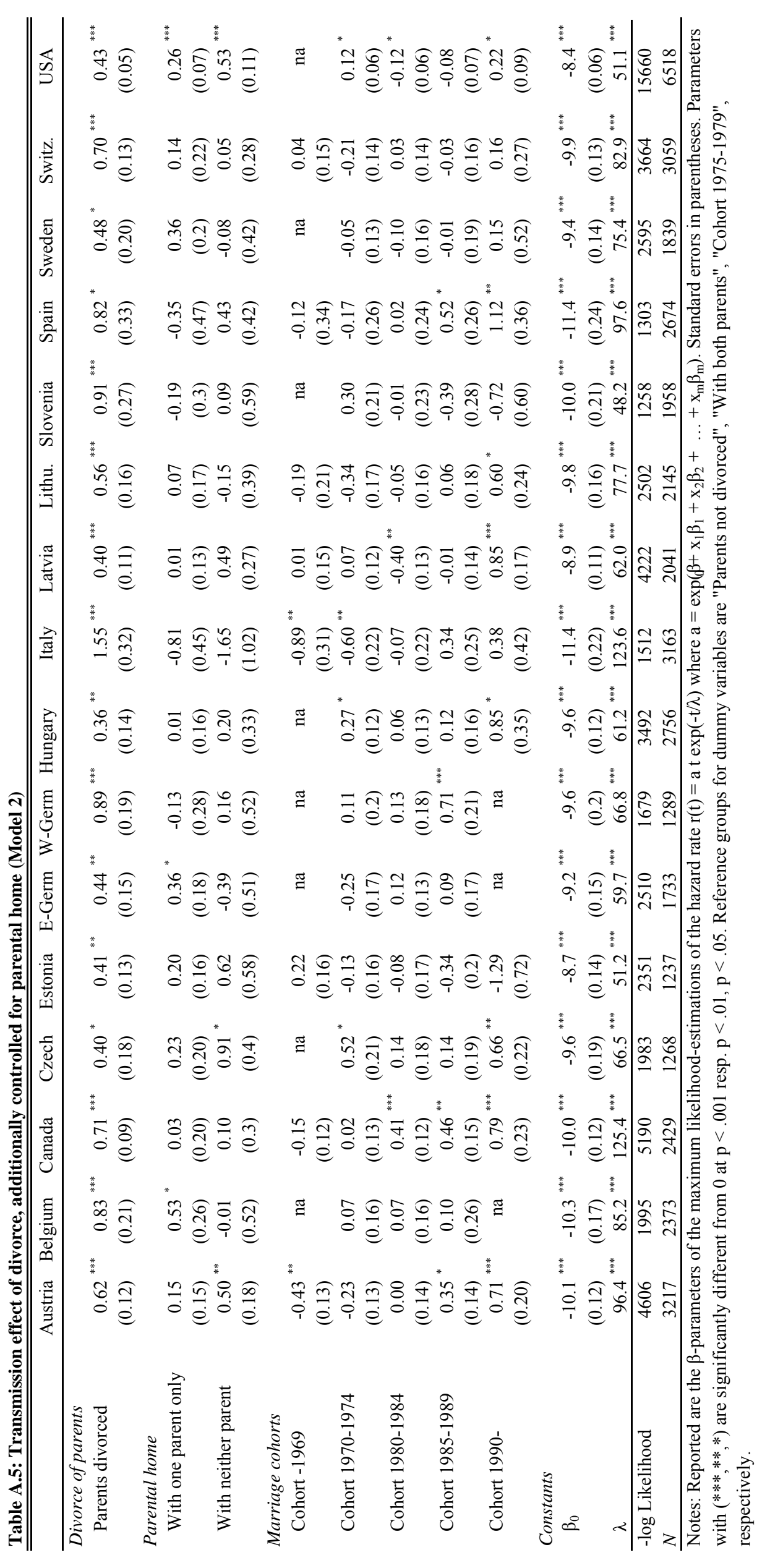




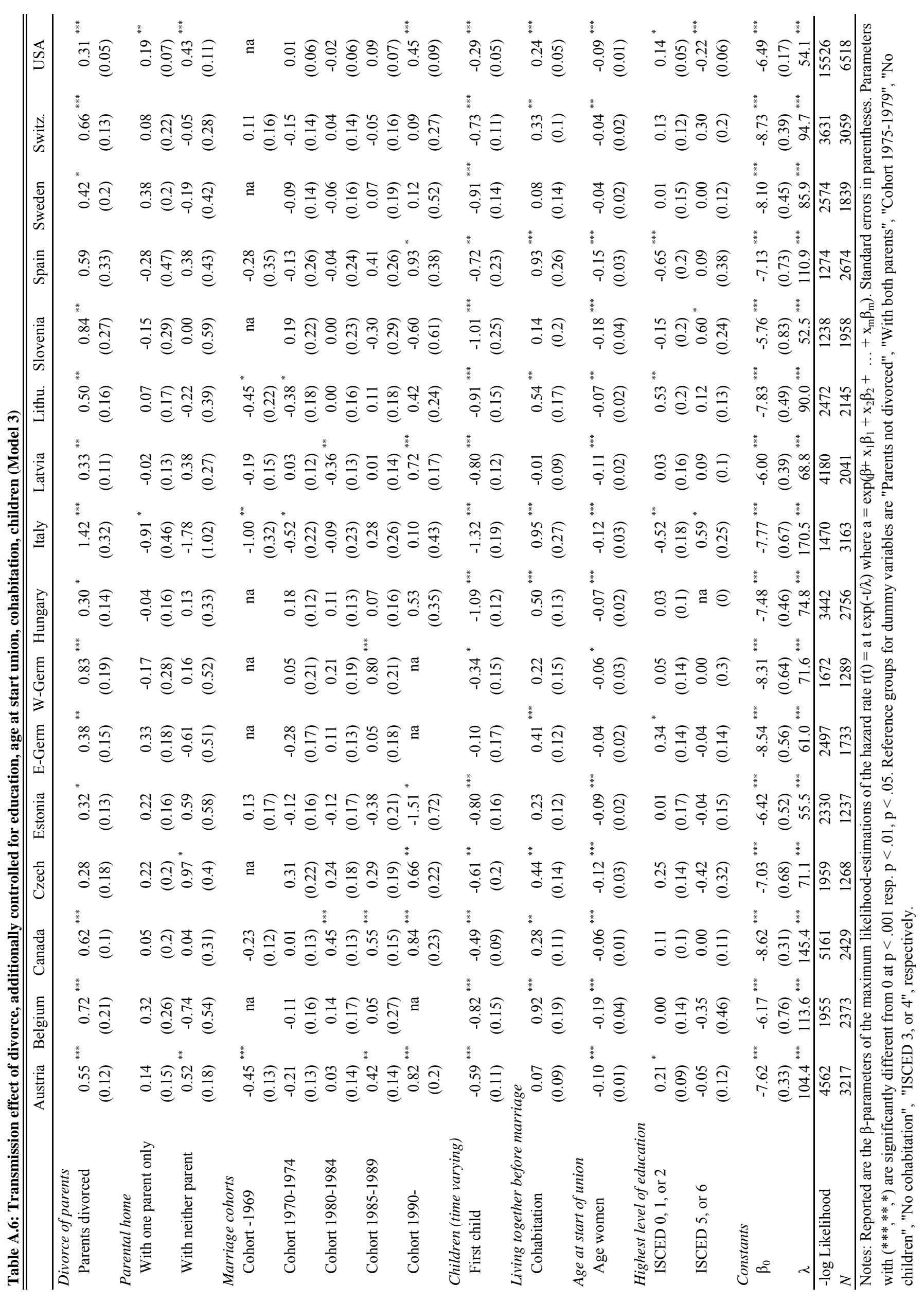

